\title{
Endovascular treatment of iatrogenic acute mesenteric ischemia
}

\section{Tratamento endovascular da isquemia mesentérica aguda iatrogênica}

\author{
Ricardo de Alvarenga Yoshida', Paulo Roberto Bahur Vieira², Winston Bonetti Yoshida ${ }^{3}$,
} Marcone Lima Sobreira ${ }^{4}$, Rodrigo Gibin Jaldin ${ }^{5}$

\section{INTRODUCTION}

Acute mesenteric ischemia is not a common condition, occurring at a rate of one case in every 1000 hospital admissions in the United States ${ }^{1}$. The majority of these cases are the result of emboli or thrombotic occlusions. This is a dangerous condition, with mortality around $60 \%$ and may require extensive bowel resection ${ }^{2}$. The primary risk factors for embolisms are atrial fibrillation, recent myocardial infarction and heart failure. Important warning signs of thrombotic occlusions include postprandial abdominal pains and food intolerance. Superior mesenteric artery (SMA) showing acute occlusion related to iatrogenic causes have received little attention in the literature and those that have been described are generally related to prior endovascular procedures $^{3-5}$. In this article we describe a case of acute occlusion of the superior mesenteric artery after conventional surgery to treat intestinal cancer by total colectomy. The occlusion was successfully resolved by endovascular surgery.

\section{PART I - THE CASE}

A 62-year old male patient with colorectal cancer underwent total colectomy surgery to treat synchronic adenocarcinoma of the ascending colon and rectum. The surgical records state that venous bleeding occurred during the operation at the level of the SMA and was staunched using several hemostatic sutures. Forty-eight hours later the patient exhibited vomiting, abdominal distension and diffuse abdominal pains, suggesting an acute abdomen case. He underwent angiotomography, which showed a proximal occlusion of the SMA $(2.6 \mathrm{~cm}$ long, see Figure 1).
There were some treatment options in this case:

- Explorative laparotomy;

- Endovascular treatment with revascularization of the SMA with stent placement;

- Open surgery with revascularization of the SMA with an embolectomy catheter and/or bypass.

\section{PART II - THE TREATMENT}

Considering that the patient was in postoperative recovery from major surgery, the decision to perform endovascular treatment was taken, as it was less invasive option, attempting to reverse the vascular acute abdomen caused by the initial phases of mesenteric ischemia. During the total colectomy, the inferior mesenteric artery (IMA) had been intentionally ligated compromising the Riolan Arch and there was also possible inadvertent involvement of SMA by hemostatic sutures along the superior mesenteric vein that could contribute to deficit of intestinal blood supply. Therefore, the aim of endovascular treatment would be to rescue the SMA, saving the small intestine from ischemia, which could cause intestinal necrosis, requiring bowel resection that could lead to Short Bowel Syndrome and / or septic complications.

A right femoral approach was used to perform an aortography, which only showed the celiac trunk, the renal arteries and the ostium of the SMA (arterial stump). The aorta was patent with normal blood flow, no lumen wall irregularities or parietal calcifications, not suggesting atherosclerosis. The SMA was selectively catheterized from its origin using an angiographic catheter, but a stiff hydrophilic guidewire could not cross the occlusion. The $11 \mathrm{~cm}$ sheath was therefore changed for a $45 \mathrm{~cm}$ one with

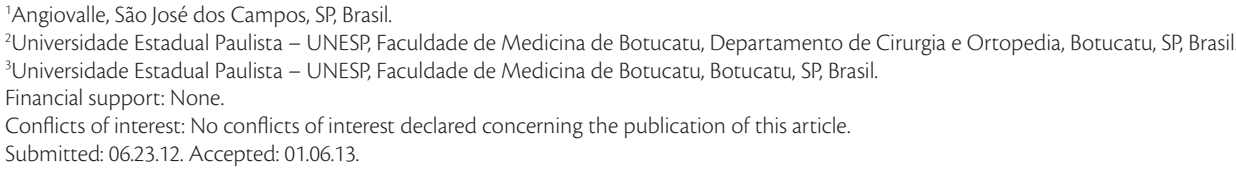




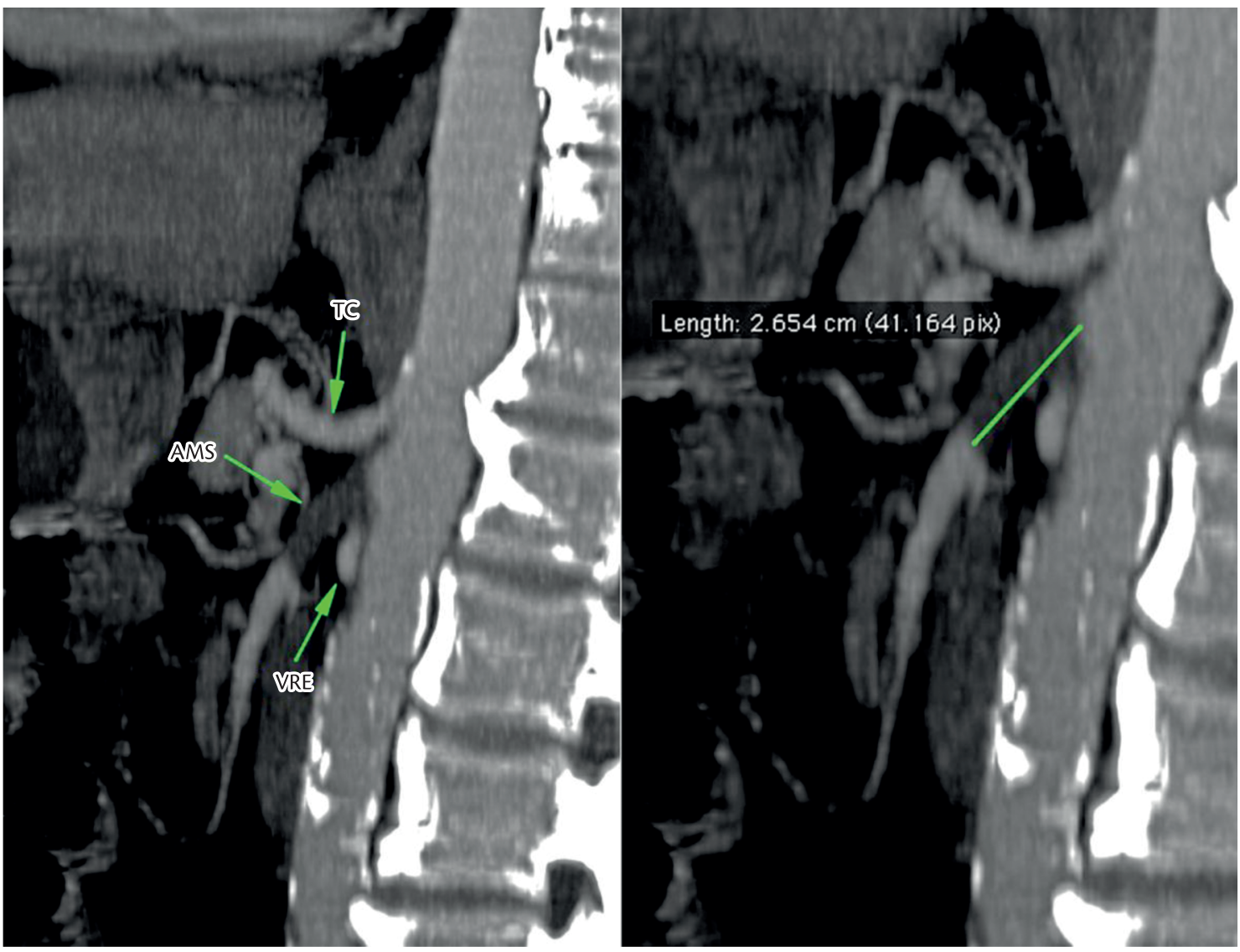

Figure 1. Preoperative showing proximal occlusion of the SMA (2.6 cm long).

an RDC curvature, in order to improve the support for endovascular devices. The SMA was once more selectively catheterized from its origin using an angiographic catheter, now supported by the longer sheath, and this time it was possible to cross the occlusive lesion with the stiff hydrophilic guidewire. Angiography showed that blood flow was normal beyond the initial occluded segment of the artery and there were no lumen wall irregularities or parietal calcifications, corroborating the hypothesis of a local iatrogenic injury (Figure 2). The stiff hydrophilic guidewire was then changed for a $0.014 \mathrm{~mm}$ extra support guidewire. Therefore an attempt was made to place a $6.0 \mathrm{~mm} \times 49 \mathrm{~mm}$ balloon-expandable stent across the occlusion at the origin of the SMA, without success. Thus it was necessary to use the "Buddy Wire" technique, using a stiff hydrophilic guide wire to help advancing the balloon-expandable stent delivery device, which was supported by the 0.014 guide wire. After the stent had been correctly placed, the stiff hydrophilic guidewire was then removed and the stent successfully expanded. Control angiography showed that the stent was well-placed, with no sign of residual stenosis and normal blood flow to the SMA (Figure 3).

The patient evaluated well, with complete remission of the symptoms of nausea and abdominal pain soon after the procedure. Abdominal distension receded over 24 hours and after 48 hours the patient was taken off the nasogastric tube and was discharged 72 hours after surgery.

Three weeks after the operation, a follow-up mesenteric angiotomography showed a patent stent with normal blood flow through the lumen and no sign of residual stenosis (Figure 4).

\section{DISCUSSION}

Reports on iatrogenic occlusion of the SMA during conventional gastrointestinal surgical procedures are rare. We were only able to find a single report describing iatrogenic dissection of this artery, which was treated using an endovascular procedure ${ }^{3}$. There are no prior descriptions of a similar case to this, in which the SMA was occluded by a iatrogenic injury and treated by endovascular approach. 


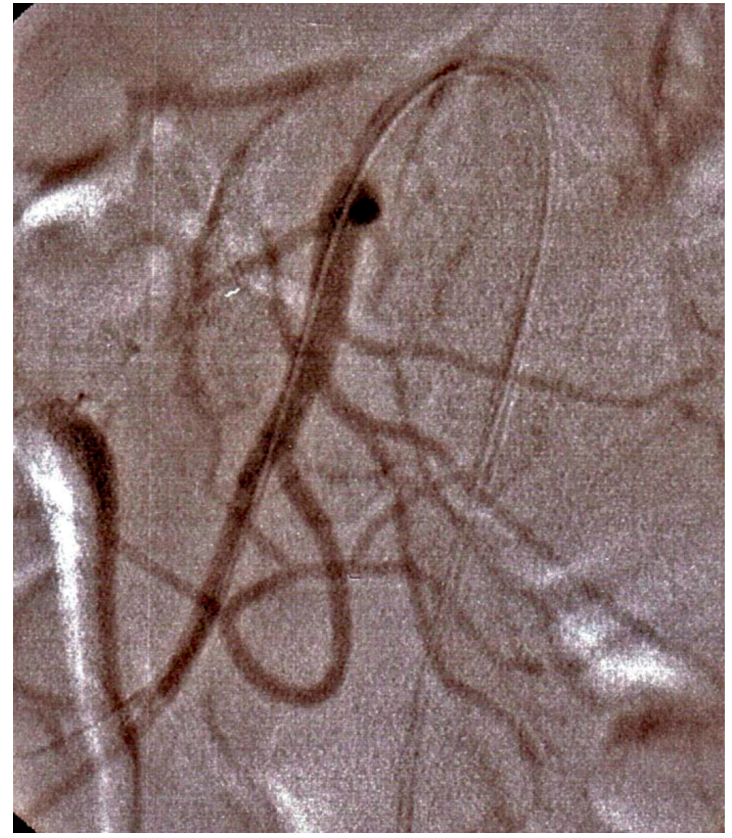

Figure 2. Intraoperative diagnostic angiography - critical stenosis detected on passing the occlusion at the initial injured section of the SMA.

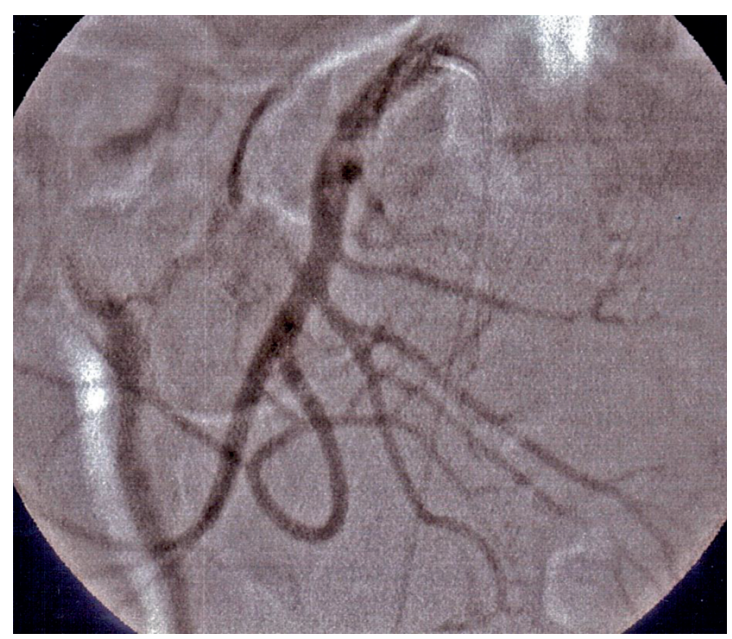

Figure 3. Control angiography - showing the stent welllocated, no signs of residual stenosis and normal blood flow through the SMA.

Suspected SMA occlusion can be confirmed by ultrasound, angiocomputerized tomography or angiography. The treatment options for acute cases are: laparotomy with embolectomy; saphenous vein or synthetic grafts bypasses; hybrid de-obstruction procedures ${ }^{4,67} ;$ or endovascular angioplasty with stent placement (primarily for thrombotic occlusions) $)^{1}$. It is also possible to perform thrombolysis followed

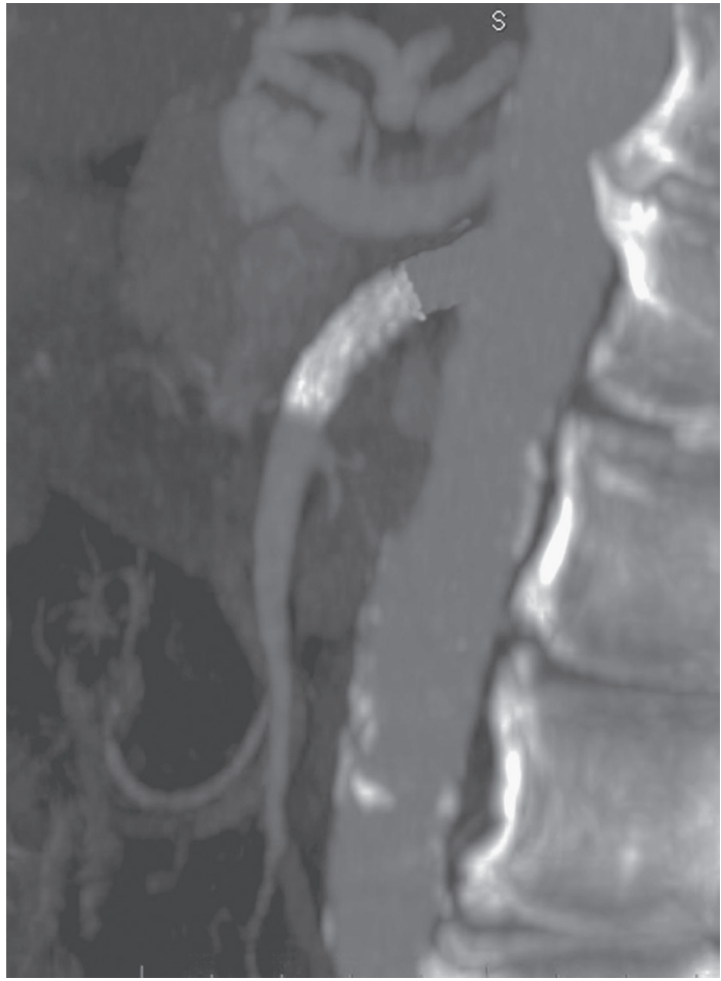

Figure 4. Follow-up control angiotomography 3 weeks after surgery showing a patent stent with normal blood flow through the lumen and no signs of residual stenosis.

by angioplasty with stent $^{8,9}$, which is primarily used in cases when the obstruction has reached more distal portions of the artery ${ }^{10-13}$. However, although preliminary thrombolysis prevents distal mesenteric embolisms, it can also cause hemorrhagic complications and was therefore contraindicated in this case by the recent major surgery.

In the case described here, there was a short occluded segment, without injury to distal portions, possibly provoked by the iatrogenic stenosis, and, since there were only recently-formed, small, unorganized thrombosis, catheterization itself was performed without major difficulties. However, the task of advancing the balloon-expanded stent through the occluded injured segment presented technical difficulty. The "Buddy Wire" technique facilitated progression of balloon-expandable shaft and its placement, making it possible to release the stent successfully and restore blood flow to the artery, avoiding severe mesenteric ischemia complications.

Observation of a larger number of cases will be necessary before this technique could be proposed as the most viable option or the method of choice in these cases. Notwithstanding, in this case the technique avoided the need for re-laparotomy or 
for even more invasive techniques to repair vessels, in a patient who had already been debilitated by his underlying disease and the extensive nature of the prior surgery he had undergone. This treatment also avoided the need for more radical intestinal resection, sparing the patient from the symptoms associated with a Short Intestinal Syndrome and from the complications associated with necrosis or a perforated bowel, while also guaranteeing a more easily tolerated postoperative recovery process.

\section{REFERENCES}

1. Wyers MC. Mesenteric Vascular Disease: Acute Ischemia. In: Cronenwett JL, Johnston KW, editors. Rutherford's Vascular Surgery. Philadelphia: Saunders, 2010. v. 2, p. 2289-2303. http:// dx.doi.org/10.1016/B978-1-4160-5223-4.00149-9

2. Sánchez Fernández P, Mier y Díaz J, Blanco Benavides R. Isquemia mesentérica aguda: semblanza de una enfermedad agresiva; Acute mesenteric ischemia: the face of an aggressive disease. Rev Gastroenterol Méx. 2000;65:134-140. PMid:11464607.

3. Murphy TP, Dorfman GS, Segall M, Carney Junior WI. latrogenic arterial dissection: treatment by percutaneous transluminal angioplasty. Cardiovasc Intervent Radiol. 1991;14:302-6. PMid:1834338. http://dx.doi.org/10.1007/BF02578455

4. Sonesson B, Hinchliffe RJ, Dias NV, Resch TA, Malina M, Ivancev K. Hybrid recanalization of superior mesenteric artery occlusion in acute mesenteric ischemia. J Endovasc Ther. 2008;15:129-32. PMid:18254664. http://dx.doi.org/10.1583/07-2210.1

5. Oderich GS, Tallarita T, Gloviczki P, et al. Mesenteric artery complications during angioplasty and stent placement for atherosclerotic chronic mesenteric ischemia. J Vasc Surg. 2012;55:1063-71. PMid:22322121. http://dx.doi. org/10.1016/j.jvs.2011.10.122

6. Stout $\mathrm{CL}$, Messerschmidt CA, Leake AE, Veale WN, Stokes GK, Panneton JM. Retrograde open mesenteric stenting for acute mesenteric ischemia is a viable alternative for emergent revascularization. Vasc Endovascular Surg. 2010;44:368-71. PMid:20484073. http://dx.doi.org/10.1177/1538574410369568

7. Wyers MC, Powell RJ, Nolan BW, Cronenwett JL. Retrograde mesenteric stenting during laparotomy for acute occlusive mesenteric ischemia.J Vasc Surg. 2007;45:269-75. PMid:17264001. http://dx.doi.org/10.1016/j.jvs.2006.10.047

8. Zhang XT, Zhang HY, Zhang W, et al. [Acute superior mesenteric ischemia: a contrast study on short-and mid-term result between stent implantation and pharmaceutical thrombolysis]. Zhonghua Yi Xue Za Zhi. 2011;91:473-6. PMid:21418979.
9. Resch TA, Acosta S, Sonesson B. Endovascular techniques in acute arterial mesenteric ischemia. Semin Vasc Surg. 2010;23:29-35. PMid:20298947. http://dx.doi.org/10.1053/j. semvascsurg.2009.12.004

10. Gartenschlaeger S, Bender S, Maeurer J, Schroeder RJ. Successful percutaneous transluminal angioplasty and stenting in acute mesenteric ischemia. Cardiovasc Intervent Radiol. 2008;31:398 400. PMid:17205365. http://dx.doi.org/10.1007/s00270-006-0147-z

11. Hawkins BM, Khan Z, Abu-Fadel MS, Exaire JE, Saucedo JF, Hennebry TA. Endovascular treatment of mesenteric ischemia. Catheter Cardiovasc Interv. 2011;78:948-52. PMid:21523886. http://dx.doi.org/10.1002/ccd.23098

12. Gagniere J, Favrolt G, Alfidja A, et al. Acute thrombotic mesenteric ischemia: primary endovascular treatment in eight patients. Cardiovasc Intervent Radiol. 2011;34:942-8. PMid:21717248. http://dx.doi.org/10.1007/s00270-011-0212-0

13. Demirpolat G, Oran I, Tamsel S, Parildar M, Memis A. Acute mesenteric ischemia: endovascular therapy. Abdom Imaging. 2007;32:299-303. PMid:16967242. http://dx.doi. org/10.1007/s00261-006-9074-3

Correspondence

Ricardo de Alvarenga Yoshida FMB-UNESP

Av. Bento Lopes, 679 - Rubião Junior CEP 18618-970 - Botucatu (SP), Brazil Fone: (14) 3811-6269

E-mail: ricardoyoshida@gmail.com

Author contributions

RAY is a vascular and endovascular surgeon at Angiovalle Collaborating professor in the discipline of Vascular and Endovascular Surgery at Faculdade de Medicina de Botucatu (FMB), Universidade Estadual Paulista (UNESP); PhD, Department of Surgery and Orthopedics, FMB (UNESP).

PRBV is a vascular and endovascular surgeon at Angiovalle. WBY is full professor and chief of the Service of Vascular and Endovascular Surgery at FMB (UNESP)

MLS is assistant professor of the Service of Vascular and Endovascular Surgery at FMB (UNESP)

RG) is assistant physician of the Service of Vascular and Endovascular Surgery at FMB (UNESP), Department of Surgery and Orthopedics, FMB (UNESP)

Author information Conception and design: RAY, WBY Analysis and interpretation: RAY, WBY Data collection: RAY, WBY, PRBV, MLS, RG) Writing the article: RAY, WBY

Critical revision of the article: RAY, WBY Final approval of the article*: RAY, WBY, PRBV, MLS, RG Statistical analysis: N/A Overall responsibility: RAY

*All authors have read and approved the final version submitted to J Vasc Bras 